\title{
Chemotherapy-resistant osteosarcoma is highly susceptible to IL-15-activated allogeneic and autologous NK cells
}

\author{
Emilie P. Buddingh • Marco W. Schilham • S. Eriaty N. Ruslan • Dagmar Berghuis • \\ Karoly Szuhai - Jolien Suurmond - Antonie H. M. Taminiau • Hans Gelderblom • \\ R. Maarten Egeler · Massimo Serra • Pancras C. W. Hogendoorn · Arjan C. Lankester
}

Received: 10 October 2010/Accepted: 22 December 2010/Published online: 15 January 2011

(C) The Author(s) 2011. This article is published with open access at Springerlink.com

\begin{abstract}
High-grade osteosarcoma occurs predominantly in adolescents and young adults and has an overall survival rate of about $60 \%$, despite chemotherapy and surgery. Therefore, novel treatment modalities are needed to prevent or treat recurrent disease. Natural killer (NK) cells are lymphocytes with cytotoxic activity toward virusinfected or malignant cells. We explored the feasibility of autologous and allogeneic NK cell-mediated therapies
\end{abstract}

Electronic supplementary material The online version of this article (doi:10.1007/s00262-010-0965-3) contains supplementary material, which is available to authorized users.

E. P. Buddingh - M. W. Schilham - S. E. N. Ruslan

D. Berghuis - J. Suurmond · R. M. Egeler ·

A. C. Lankester $(\square)$

Department of Pediatrics, Leiden University Medical Center, PO Box 9600, 2300 RC Leiden, The Netherlands

e-mail: A.Lankester@lumc.nl

D. Berghuis · P. C. W. Hogendoorn

Department of Pathology, Leiden University Medical Center,

PO Box 9600, 2300 RC Leiden, The Netherlands

\section{K. Szuhai}

Department of Molecular Cell Biology, Leiden University

Medical Center, PO Box 9600, 2300 RC Leiden,

The Netherlands

A. H. M. Taminiau

Department of Orthopedic Surgery, Leiden University Medical Center, PO Box 9600, 2300 RC Leiden, The Netherlands

H. Gelderblom

Department of Clinical Oncology, Leiden University Medical Center, PO Box 9600, 2300 RC Leiden, The Netherlands

M. Serra

Laboratorio di Oncologia Sperimentale, Istituto Ortopedico

Rizzoli, Via di Barbiano 1/10, 40136 Bologna, Italy for chemotherapy-resistant and chemotherapy-sensitive high-grade osteosarcoma. The expression by osteosarcoma cells of ligands for activating NK cell receptors was studied in vitro and in vivo, and their contribution to NK cellmediated cytolysis was studied by specific antibody blockade. Chromium release cytotoxicity assays revealed chemotherapy-sensitive and chemotherapy-resistant osteosarcoma cell lines and osteosarcoma primary cultures to be sensitive to NK cell-mediated cytolysis. Cytolytic activity was strongly enhanced by IL-15 activation and was dependent on DNAM-1 and NKG2D pathways. Autologous and allogeneic activated NK cells lysed osteosarcoma primary cultures equally well. Osteosarcoma patientderived NK cells were functionally and phenotypically unimpaired. In conclusion, osteosarcoma cells, including chemoresistant variants, are highly susceptible to lysis by IL-15-induced NK cells from both allogeneic and autologous origin. Our data support the exploitation of NK cells or NK cell-activating agents in patients with high-grade osteosarcoma.

Keywords Osteosarcoma - Immunotherapy - NK cells · Bone sarcoma

\section{Introduction}

High-grade osteosarcoma is the most common primary malignant bone sarcoma, occurring mainly in adolescents and young adults [1]. Despite multi-agent chemotherapy and surgery, overall survival is still poor at about sixty percent [2-4]. Therefore, novel treatment modalities are urgently needed to either prevent or treat chemotherapy refractory and recurrent disease. Immunomodulatory agents such as interferon (IFN)- $\alpha$ and muramyl-tri-peptide 
(MTP) have been added to standard chemotherapy regimens in recent clinical trials [5-7]. Immunotherapy with stimulatory cytokines such as IL-2 and IL-15 or the adoptive transfer of ex vivo cytokine-activated cytotoxic lymphocytes such as natural killer (NK) cells could be another adjunct to current therapy [8-10].

NK cells lack a clonally rearranged antigen-specific receptor. Instead, cytolytic activity toward virus-infected or malignant cells is dependent on the balance between inhibitory and activating signals. NK cell-activating signals are provided when the activating receptors Natural Killer Group 2, member D (NKG2D), DNAX accessory molecule-1 (DNAM-1), and the natural cytotoxicity receptors (NCRs) NKp30, NKp44, and NKp46 bind their respective ligands [11-13]. Although NK cell recognition of tumor cells has been reported to be partially mediated through NCRs, the responsible ligands are unknown [14]. The DNAM-1 ligands poliovirus receptor (PVR, CD155) and Nectin-2 (CD112) are highly expressed by many tumors, including sarcomas [13, 15, 16]. Ligands for NKG2D are the stress-inducible major histocompatibility class I polypeptide-related sequence (MIC) A and B and the UL-16-binding proteins (ULBPs) 1-4. Inhibitory ligands are the classical and non-classical human leukocyte antigen (HLA) class I molecules expressed on all normal cells [17]. These ligands bind to inhibitory killer immunoglobulin receptors (KIRs) and the C-type lectin heterodimer CD94/NKG2A on NK cells, respectively. In addition to high expression of NKG2D and DNAM-1 ligands, many tumors show loss of HLA class I, possibly rendering them susceptible to NK cell-mediated lysis [18, 19].

In the current study, we demonstrated the sensitivity of chemotherapy-resistant and chemotherapy-sensitive osteosarcoma cells to lysis by IL-15-activated NK cells and identified the molecular mechanisms involved. NK cells of osteosarcoma patients were not functionally impaired and were able to lyse autologous tumor cells, supporting the use of NK cell-activating agents in the treatment of osteosarcoma patients.

\section{Materials and methods}

\section{Patient material}

A tissue array was constructed from formalin-fixed, paraffinembedded (FFPE) tissue retrospectively collected from 88 osteosarcoma patients treated at the LUMC as previously described [20] (Suppl. Table 1). Peripheral blood mononuclear cells (PBMCs) were collected from healthy controls and 22 pre-treatment osteosarcoma patients after written informed consent was obtained, as approved by the Institutional Review Board on Medical Ethics. Osteosarcoma tissue samples were used for research in accordance with national ethical guidelines (Code for Proper Secondary Use of Human Tissue, Dutch Federation of Medical Scientific Societies). All patient material was handled in a coded fashion. Clinical and pathological details of all patients can be found in Suppl. Table 2.

\section{Cell lines and primary cultures}

The osteosarcoma cell lines HOS, 143B/HOS, IOR-OS14, SJSA-1, OHS, ZK-58, U2-OS, and SAOS-2 were characterized and maintained as described earlier [21]. The EBV B-LCL cell line 107 (EBV) and the erythroleukemic cell line K562 were maintained in RPMI 1640 medium (Invitrogen, Carlsbad, CA) supplemented with $10 \%$ fetal calf serum (FCS, Invitrogen) and $1 \%$ penicillin/streptomycin (PS, Invitrogen). The chemotherapy-resistant variant cell lines of U2-OS and SAOS-2 were established as described previously [22-24] and were maintained in Iscove's modified Dulbecco's medium (IMDM, Invitrogen) supplemented with 10\% FCS and PS. The doxorubicin (DX)-resistant variants U2-OS-DX580 and SAOS-2-DX580 were cultured in the presence of $580 \mu \mathrm{g} / \mathrm{ml} \mathrm{DX}$. The methotrexate (MTX)resistant variants U2-OS-MTX300 and SAOS-2-MTX1 $\mu \mathrm{g}$ were cultured in the presence of 300 and 1,000 ng/ml MTX, respectively. The cisplatin (cis-diamminedichloroplatinum, CDDP)-resistant variants U2-OS-CDDP4 $\mu \mathrm{g}$ and SAOS2CDDP6 $\mu \mathrm{g}$ were cultured in the presence of 4 and $6 \mu \mathrm{g} / \mathrm{ml}$ CDDP, respectively.

Fresh osteosarcoma samples L2808, L2599, L2792, L2635, and L2531 were cultured as described previously by our group for related tumors [25]. Clinical and histopathological details can be found in Suppl. Table 3. L2531, L2792, and L2599 were derived from patients with poor histological response to pre-operative chemotherapy in the primary tumor. L2808, a pulmonary metastatic sample, was derived from a patient with good histological response in the primary tumor but who relapsed nonetheless. L2635 originated from a patient with good histological response to pre-operative chemotherapy who is currently in persistent first complete remission (follow-up since diagnosis 20 months). Collected tissue pieces were dissociated mechanically and cultured in RPMI 1640 medium supplemented with $20 \%$ FCS and PS. When subconfluence was reached, cells were harvested using $0.05 \%$ Trypsin/EDTA (Invitrogen) and passaged. Chromium release assays and flow cytometric analyses were performed no later than at passage 3 .

Isolation and culture of NK cells

PBMCs were isolated using a Ficoll density gradient separation followed by NK cell enrichment using the MACS 
NK enrichment kit and LS columns (Miltenyi Biotec, Bergisch Gladbach, Germany) according to the manufacturer's protocol. Purity of NK cells was assessed by flow cytometry and was typically around $95 \%$ (less than $1 \% \mathrm{~T}$ cells). NK cells were cultured in AIM-V medium (Invitrogen), supplemented with $10 \%$ pooled human $\mathrm{AB}$ serum (Sanquin, Rotterdam, the Netherlands), PS and glutamine (Glutamax I, Invitrogen). Activated NK cells were cultured with $10 \mathrm{ng} / \mathrm{ml}$ recombinant human interleukin-15 (IL-15) for 3 days or 2 weeks (Peprotech, Rocky Hill, NJ).

\section{Flow cytometry}

Surface staining of cells for flow cytometry was performed as described elsewhere [18]. Intracellular flow cytometry staining was done using permeabilization and fixation kits as per manufacturer's instructions (00-5123; 00-5223; 00-8333, eBioscience, San Diego, CA). An overview of antibodies can be found in Suppl. Table 4. Flow cytometry of PBMC of osteosarcoma patients and healthy controls was performed on a BD LSRII and analyzed using FACS Diva Software 5.0 (both from Becton-Dickinson, San Diego, CA). Mean fluorescence intensity (MFI) of cell subsets was calculated by subtracting the MFI of a negative population from the MFI of the population of interest within one individual to correct for interindividual variability of background staining. Flow cytometry of cell lines and purified NK cells was performed on a FACScalibur and analyzed using Cellquest software (both Becton-Dickinson). MFI ratio was calculated by MFI of the specific staining relative to the MFI of the appropriate isotype control staining.

\section{Immunohistochemistry}

Immunohistochemistry was performed on FFPE tissue array sections as previously described [20]. Testis was used as a positive control for the activating NK ligands and tonsil for the inhibitory ligands. Sections were blocked using $10 \%$ swine or goat serum in PBS and subsequently incubated with primary antibody diluted in $0.5 \%$ bovine serum albumin (BSA) in PBS overnight. As a negative control, $0.5 \%$ BSA/PBS without primary antibody was used. All primary antibodies are listed in Suppl. Table 4. Anti-rabbit/rat/mouse PowerVision Poly-HRP (Leica Biosystems, Newcastle Upon Tyne, United Kingdom) was used as a secondary antibody, except for the MICA staining, in which case the Universal LSAB + Kit (DAKO, Glostrup, Denmark) was used. DAB + (DAKO) was used as a chromogen. Sections were counterstained using Mayer's hematoxylin. Tissue array images were acquired using the MIRAX slide scanner (3DHISTECH, Budapest, Hungary) and analyzed using the MIRAX viewer version
1.14 (3DHISTECH). Slides were scored by two observers (EPB and PCWH) in a modified semi-quantitative scoring system as proposed by Ruiter et al. [26]. The intensity of staining was scored as $0,1,2$, or 3 indicating absent, weak, clear, or strong expression, respectively. Percentages of positive cells were scored as 0 for $0 \%, 1$ for $1-30 \%, 2$ for $31-70 \%$, and 3 for $71-100 \%$.

\section{Chromium release assays}

Cytotoxicity was determined in standard 4-h Chromium release assays. For experiments using PBMCs of OS patients and controls, PBMCs were thawed from storage in liquid nitrogen and allowed to recover for $16 \mathrm{~h}$ in RPMI 1640 supplemented with $10 \%$ FCS and PS. The E:T ratios in these experiments were corrected for the percentage of NK cells of PBMCs as determined by flow cytometry. For all other experiments, purified unstimulated or IL-15-activated NK cells were used as effector cells. Target cells (cell lines or primary cultures) were incubated with $100 \mu \mathrm{Ci}$ sodium-51-chromate (PerkinElmer, Wellesley, MA) for $1 \mathrm{~h}$. Effector cells (PBMCs, unstimulated purified NK cells, or activated NK cells) were incubated for $4 \mathrm{~h}$ with 2,500 target cells at eight effector:target (E:T) ratios in triplicate. Maximum and spontaneous release was determined by incubating targets in $2 \mathrm{~N} \mathrm{HCl}$ or medium, respectively. Supernatants were harvested and measured in a gamma-counter (Wallac, PerkinElmer). Specific lysis was determined as: (experimental release-spontaneous release)/(maximum release-spontaneous release) $\times 100 \%$. In all NK cytotoxicity experiments, K562 and EBV were used as positive and negative controls, respectively. For blocking experiments, NK cells were pre-incubated with blocking anti-NKG2D (R\&D systems, clone 149810) and/ or blocking anti-DNAM-1 (BD Pharmingen, clone DX11) at a concentration of $20 \mu \mathrm{g} / \mathrm{ml}$. To disrupt perforin/granzyme-mediated cytolysis, NK cells were pre-incubated for $2 \mathrm{~h}$ at $37^{\circ} \mathrm{C}$ with or without $1 \mu \mathrm{M}$ Concanamycin $\mathrm{A}$ (Sigma-Aldrich, Zwijndrecht, the Netherlands) prior to adding the NK cells to the target cells. To block Fas-induced apoptosis, target cells were pre-incubated with $2 \mu \mathrm{g} / \mathrm{ml}$ neutralizing anti-Fas antibody (Clone ZB4, Millipore, Temecula, CA).

Statistical analysis

Statistical analyses were performed using GraphPad Prism 5.0 (LaJolla, CA). Data with non-normal distribution or small sample size were analyzed using non-parametric methods (Mann-Whitney U, Kruskal-Wallis, Friedman, and Dunn's tests), and data with normal distribution were analyzed using parametric methods ( $t$ tests, one-way analysis of variance (ANOVA), and Bonferroni's tests). 
Survival analyses were performed using Kaplan-Meier curves and compared using the logrank method.

\section{Results}

Osteosarcoma cells are highly susceptible to IL-15-activated allogeneic NK cells

We tested eight osteosarcoma cell lines for susceptibility to cytolytic activity of freshly isolated ('unstimulated') and IL-15-cultured ('activated') healthy donor-derived NK cells. All cell lines were lysed by unstimulated allogeneic NK cells at levels comparable to the positive control cell line K562 (Fig. 1a and b). Cytolysis of all osteosarcoma cell lines was strongly enhanced when IL-15-cultured allogeneic NK cells were used.

Osteosarcoma cells express inhibitory and activating NK cell ligands

Osteosarcoma cells expressed activating NK cell ligands and HLA class I, both in vivo and in vitro (Table 1 and Fig. 2). All osteosarcoma cell lines expressed HLA class I, at least 3/5 NKG2D ligands and both DNAM-1 ligands. Expression of ligands in vivo was determined on the tissue array containing 144 samples of 88 patients. In chemotherapy-naive tumor material MICA, DNAM-1 ligands and HLA class I were also expressed, albeit at different levels (Fig. 2a). In tumor cells persisting after chemotherapy, levels of MICA, HLA class I, and $\beta-2$ microglobulin expression were unaltered but the expression levels of the DNAM-1 ligands CD112 and CD155 were significantly decreased (Fig. 2b). There was a trend for patients with high (score $>4$ ) versus low (score $\leq 4)$ expression of MICA in pre-treatment diagnostic biopsies to have better overall survival $(n=53, P$-value logrank test $=0.07)$. Expression level of HLA class I in diagnostic biopsies as determined by staining with antibodies recognizing $\beta-2$ microglobulin, HLA-A, and HLA-B/C did not correlate with tumor progression.

NK cells lyse osteosarcoma cells in a DNAM-1- and NKG2D-dependent manner

NK cell-mediated cytolysis of osteosarcoma cells was dependent on NKG2D and DNAM-1 pathways, as was demonstrated by blocking DNAM-1, NKG2D, or both receptors (Fig. 3). In resting NK cells, the DNAM-1 pathway appeared to predominate the cytolytic potential, whereas the contribution of the NKG2D pathway was more prominent in the cytolytic activity of IL-15-cultured NK cells. In case of IL-15-cultured NK cells, blockade of both pathways was required for the optimal inhibition of NK cytolytic activity. Levels of expression of HLA class I did not correlate with magnitude of lysis by unstimulated or IL-15-activated NK cells. Similarly, levels of expression of ligands for the activating receptors NKG2D or DNAM-1 did not correlate with degree of lysis by NK cells (data not shown).
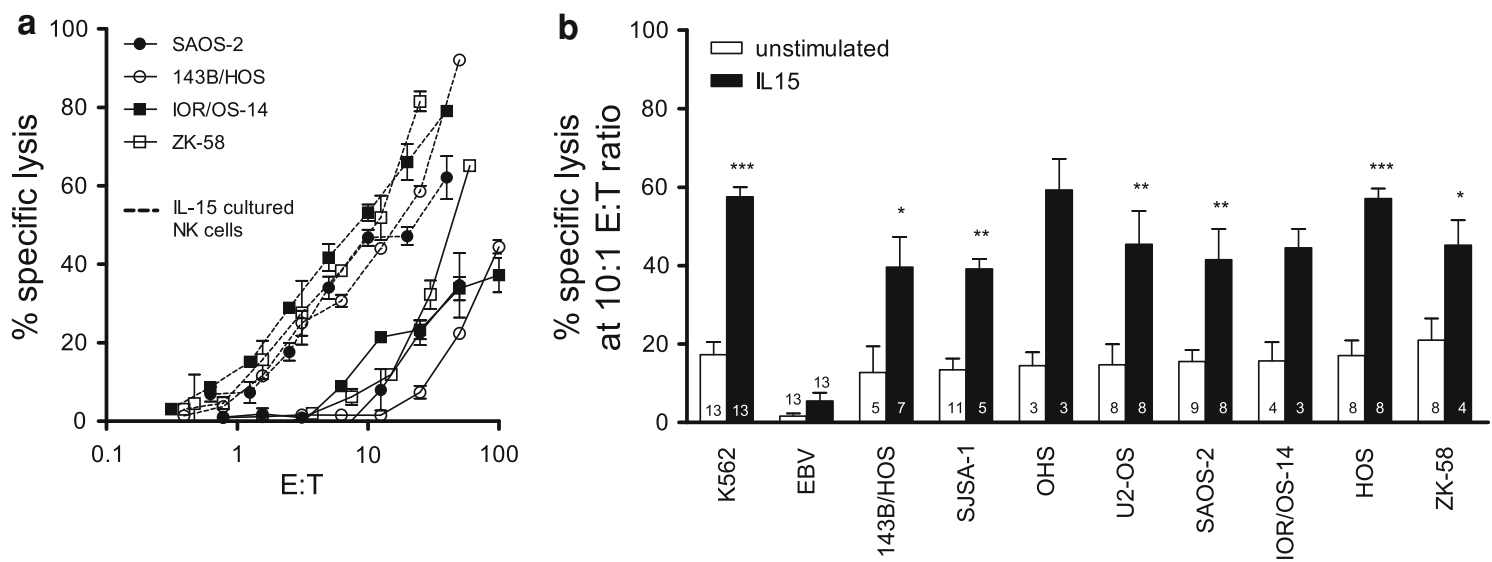

Fig. 1 Osteosarcoma cells were sensitive to lysis by freshly isolated NK cells (solid lines) and NK cells cultured in IL-15 for 2 weeks (dashed lines). a examples of percentage of specific lysis are shown for the osteosarcoma cell lines SAOS-2 (filled circle), 143B/HOS (open circle), IOR/OS-14 (filled square), and ZK-58 (open square). Cell lines were incubated with increasing numbers of NK cells (E:T; effector to target ratio). Error bars represent standard error of the mean lysis of a representative experiment performed in triplicate. b mean percentage of specific lysis by unstimulated (white bars) and IL-15-activated (black bars) NK cells of the osteosarcoma cell lines
143B/HOS, SJSA-1, OHS, U2-OS, SAOS-2, IOR/OS-14, HOS, and ZK-58 at an effector to target ratio of 10:1. Error bars represent standard error of the mean of independent experiments using different healthy donor NK cells. Numbers in the bars represent number of experiments. K562 and an EBV-transformed B-LCL ("EBV") were used as positive and negative controls, respectively. Mann-Whitney $\mathrm{U}$ test was done comparing IL-15-activated NK cells with unstimulated NK cells for each cell line; $P$-value $<0.05$ noted as $* ;<0.01$ as $* * ;<0.001$ as $* * *$ 


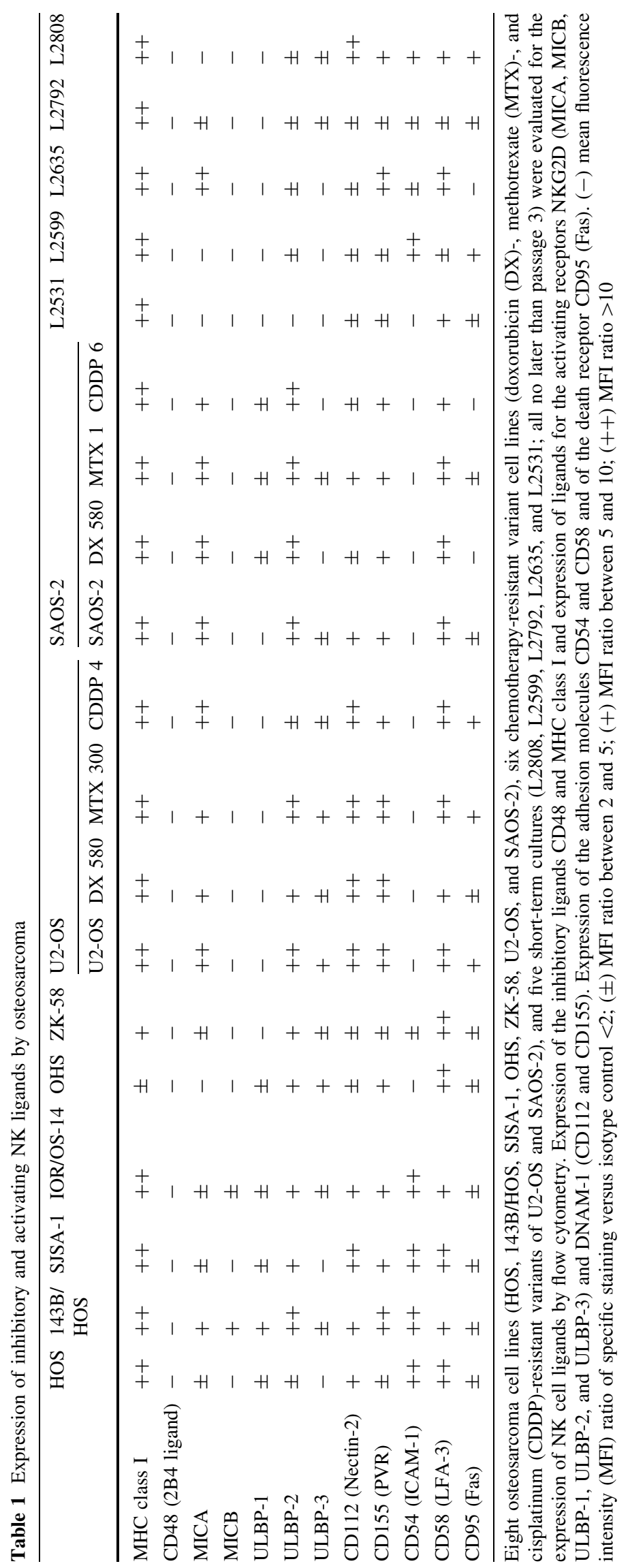




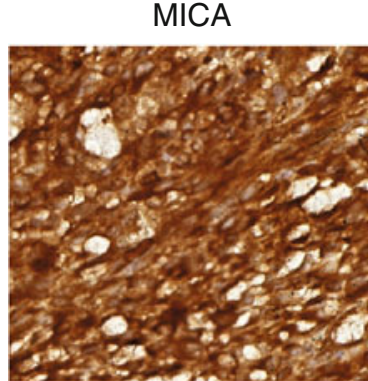

$\beta-2$ microglobulin

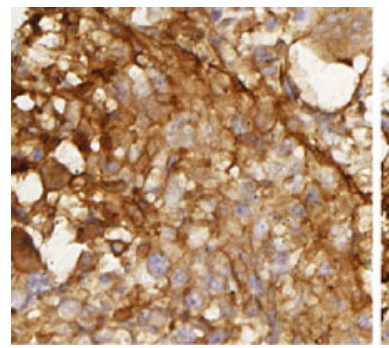

$100 \mu \mathrm{M}$
CD112

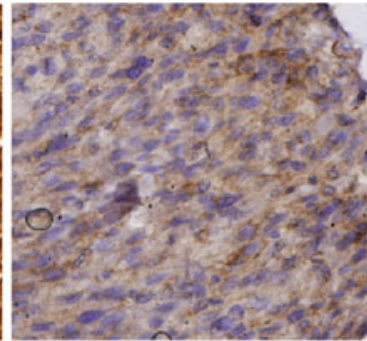

HCA2
CD155

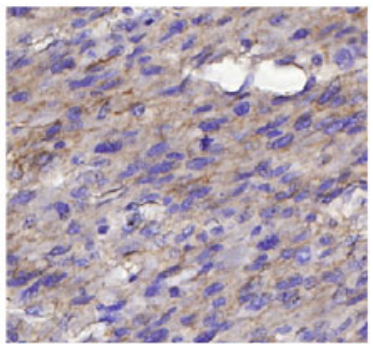

$\mathrm{HC} 10$
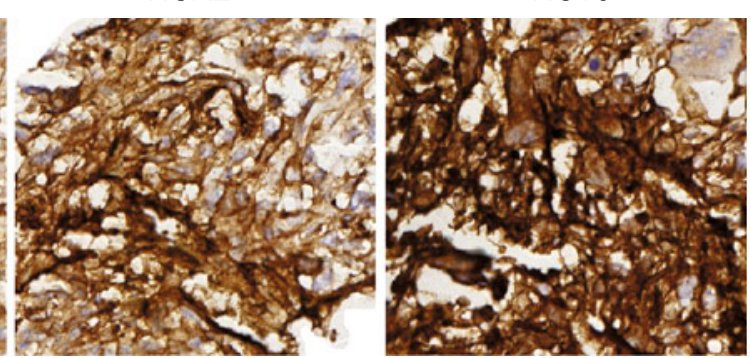

b

NK ligands in vivo

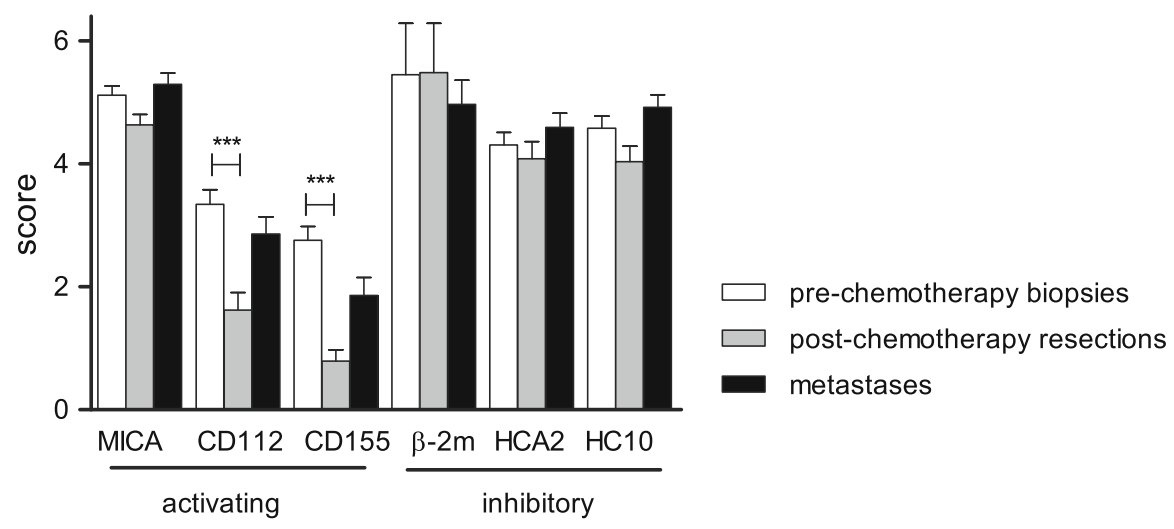

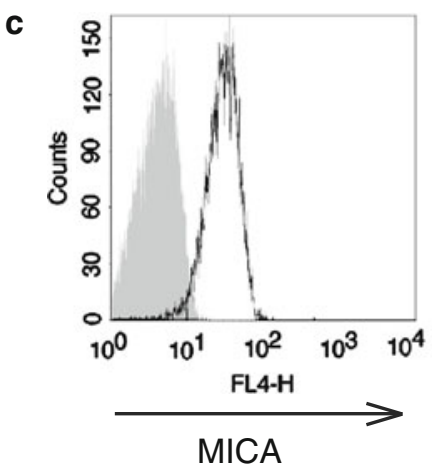

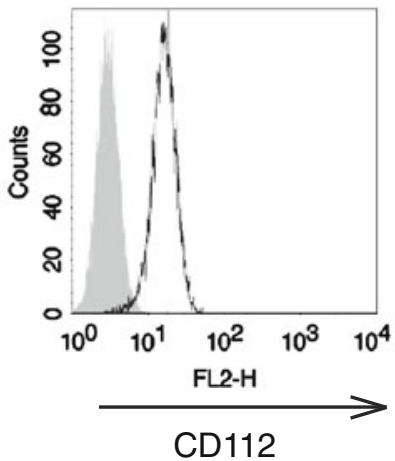

Fig. 2 a Examples of immunohistochemical staining of ligands for the activating receptors NKG2D (MICA) and DNAM-1 (CD112 and CD155) and of $\beta 2$-microglobulin, HLA-A (HCA2), and HLA-B/C (HC10) on osteosarcoma samples. b Overview of the results of immunohistochemical stainings on pre-chemotherapy and post-chemotherapy samples of the primary tumor as well as metastatic
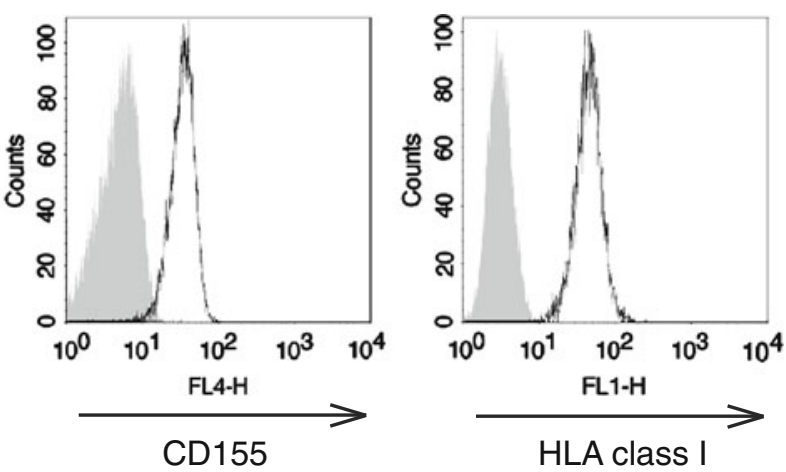

osteosarcoma tissue. Expression levels of CD112 and CD155 but not the other ligands decreased significantly upon chemotherapy treatment $(P$-value Kruskal-Wallis test $<0.001$ as $* * *)$. c Example of flow cytometry plots for MICA, CD112, CD155, and HLA class I for the osteosarcoma cell line IOR/OS-14; isotype-matched control staining is shown in gray 


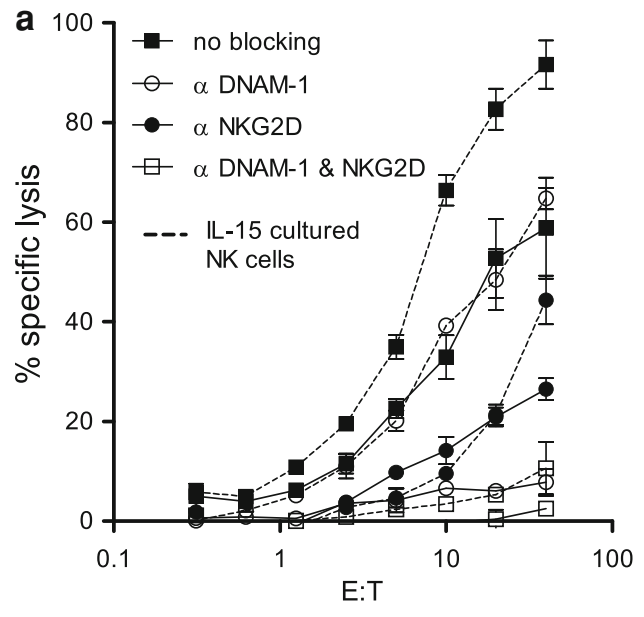

Fig. 3 a cytolysis of U2-OS by unstimulated (solid lines) and IL-15activated (dashed lines) NK cells was almost completely abrogated when the NK cells were pre-incubated with both anti ( $\alpha$ )-DNAM-1and $\alpha$-NKG2D-blocking antibodies (filled square vs. open square). Unstimulated NK cells were most dependent on DNAM-1 (open circle) signaling, whereas activated NK cells were most dependent on NKG2D (filled circle). Error bars represent standard error of the

Chemotherapy-resistant osteosarcoma cells remain sensitive to lysis by IL-15-activated NK cells

To study whether chemotherapy-resistant cell lines have become resistant to NK cell-mediated lysis as well, the sensitivity of a panel of chemotherapy-resistant variants of the osteosarcoma cell lines SAOS-2 and U2-OS (selected in vitro to be resistant to DX, CDDP or MTX) to lysis by NK cells was tested (Fig. 4a). Although some SAOS variants, e.g., CDDP, were less sensitive to lysis by resting NK cells, activation of NK cells with IL-15 greatly enhanced the lysis of all U2-OS and SAOS-2 chemotherapy-resistant variant cell lines (Fig 4a). Expression levels of NKG2D and DNAM-1 ligands were similar in chemotherapy-resistant variants and parental cell lines, as was the dependency on NKG2D and DNAM-1 signaling in cytotoxicity assays (Table 1 and Suppl. Fig. 1). Expression levels of HLA class I and of the adhesion molecules ICAM-1 and LFA-3 were unaltered in the chemotherapyresistant variants, but expression of CD95 (death receptor Fas) was lost in the SAOS-2 CDDP- and DX-resistant
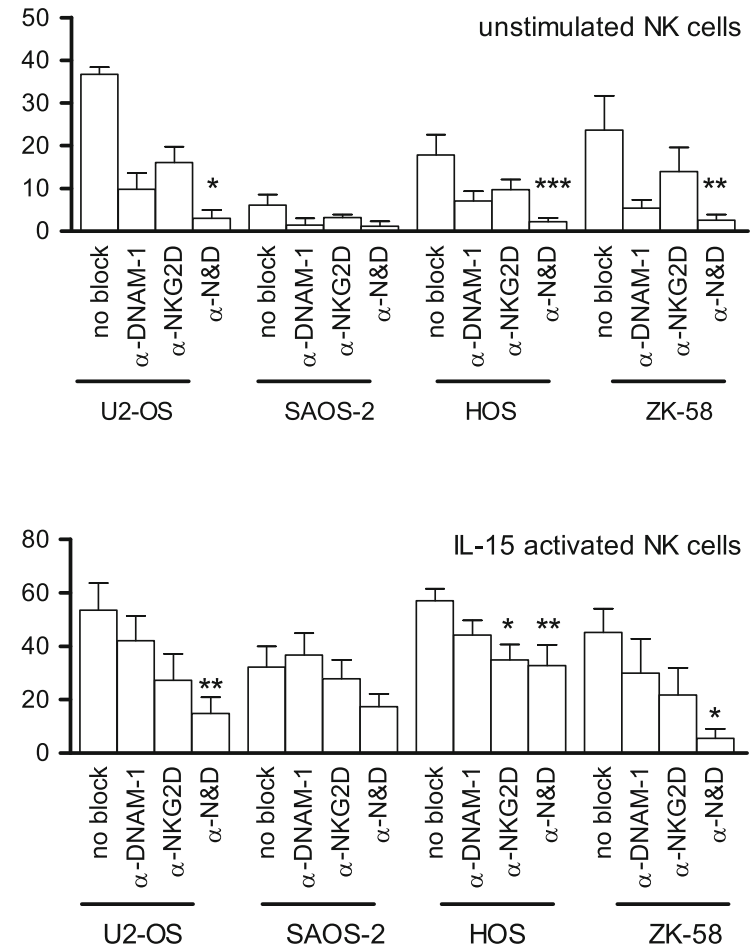

mean lysis of experiment performed in triplicate. Similar results were obtained for SAOS-2, HOS, and ZK-58 using unstimulated (b) and IL-15-activated NK cells (c). Bars represent mean lysis in at least three independent experiments using healthy donor NK cells; error bars represent standard error of the mean. Friedman test, Dunn's posttest compared to non-blocked; $P$-value $<0.05$ noted as $* ;<0.01$ as $* * ;<0.001$ as $* * *$

variants (Table 1 and Fig. 4b). Since the loss of CD95 could provide an explanation for reduced susceptibility to NK cell-induced lysis, we performed blocking experiments in which both CD95 and the granule exocytosis pathway were blocked with a blocking antibody and Concanamycin A, respectively. These experiments were performed using IL-15-activated NK cells at an effector to target ratio of 40-1. Blocking the GrB but not the CD95 cytolytic pathway almost completely abrogated NK cytolytic potential, demonstrating the predominance of the granzymeB pathway in NK cell-mediated lysis of parental as well as CDDP-resistant variants of osteosarcoma cells (Fig. 4c). Similar results were obtained when the U2-OS parental cell line was used (data not shown).

Peripheral blood NK cell phenotype is unaltered and cytolytic potential is unimpaired in newly diagnosed osteosarcoma patients

Since peripheral NK cells in patients with other tumor types show altered phenotype and function, we analyzed 
a

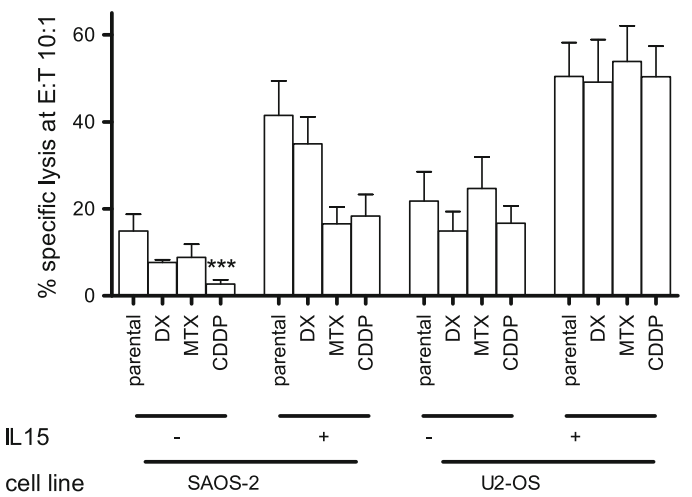

b

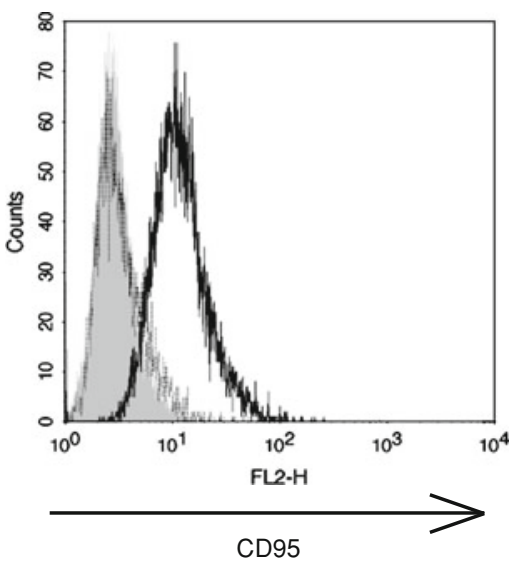

C

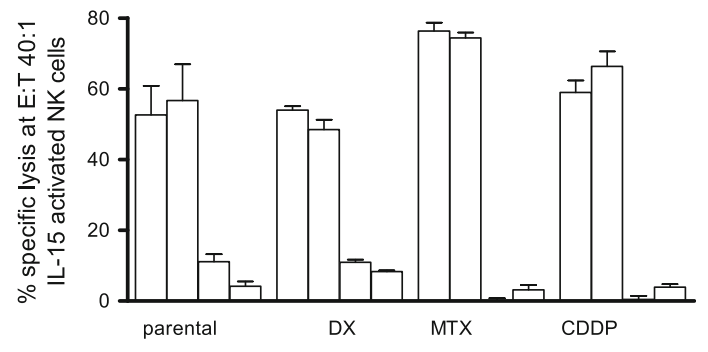

Concanamycin A $-\quad-\quad+\quad-\quad-\quad+\quad+\quad-\quad++\quad-\quad++$

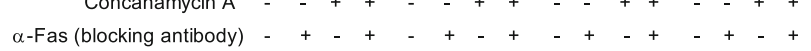

Fig. 4 a Lysis of U2-OS variants resistant to doxorubicin (DX), methotrexate (MTX), or cisplatinum (CDDP) was comparable to lysis of the parental control. The SAOS-2 CDDP-resistant line was less sensitive to lysis by unstimulated NK cells than its parental control (Friedman test $P$-value $=0.001$ and Dunn's post-test compared to parental cell line $P$-value $<0.001$ ). NK cell activation ("IL-15+") increased lysis in all cases. Error bars represent standard error of the mean lysis in at least six independent experiments. b SAOS-2 expressed the death receptor CD95 (Fas; black line), whereas expression was lost in the cisplatinum-resistant variant of SAOS-2 (dashed line). Isotype-matched control staining is shown in gray. $\mathbf{c}$ the granzyme/perforin pathway was the main cytotoxic pathway by which NK cells lysed SAOS-2 and its chemotherapy-resistant variants, as shown by inhibition of granule exocytosis by concanamycin A. Blocking Fas resulted in a further decrease in the lysis of SAOS-2, but not of the chemotherapy-resistant variants. Bars represent mean lysis of experiment performed in triplicate; error bars represent standard error of the mean. Similar results were obtained using NK cells from another donor
PBMCs of 22 newly diagnosed osteosarcoma patients and 23 age-matched healthy controls by flow cytometry for NK cell number and phenotype (Suppl. Fig. 2a). NK cell number and phenotype were comparable between patients and controls (Fig. 5a and Suppl. Fig. 2b and c). Following 3 days of culture in IL-15, there was a larger increase in NKG2D and granzyme B expression levels on both CD56dim and bright NK cells of osteosarcoma patients than of healthy controls (Fig. 5a and Suppl. Fig. 2c). We assessed the functionality of $\mathrm{NK}$ cells of osteosarcoma patients at diagnosis in cytotoxicity assays using unstimulated and 3 days IL-15-activated PBMCs as effector cells. Resting NK cells from osteosarcoma patients and healthy donors lysed the allogeneic target HOS equally well (Fig. 5b), but IL-15-cultured NK cells of patients lysed HOS significantly better than healthy donor NK cells (ANOVA, Bonferroni's post-test $P$-value $<0.0001$ ). Percentage specific lysis of HOS correlated with the level of NKG2D expression on CD56 dim NK cells (Fig. 5c; Pearson correlation efficient $r^{2} 0.45, P$-value $\left.<0.0001\right)$, and similar results were obtained for the correlation with granzyme B expression (not shown). To test whether the functional integrity of NK cells from osteosarcoma patients was also preserved toward autologous tumor cells, we took advantage of the fact that we were able to derive short-term cultured cells from fresh biopsies. Autologous, patientderived NK cells lysed short-term cultured tumor cells to a similar degree as allogeneic NK cells from healthy controls (Fig. 5d). In all cases, culture of both autologous and allogeneic NK cells in IL-15 resulted in greatly enhanced tumor cell killing.

\section{Discussion}

There is increasing interest in the potential for NK cells to be used in the treatment of pediatric solid tumors [27]. Previous studies have shown that osteosarcoma cell lines may be sensitive to cytokine-activated NK cell-mediated cytotoxicity [28-36]. However, little is known about the mechanisms involved or the extent to which short-term cultured or chemotherapy-resistant osteosarcoma cells are susceptible to NK cell-mediated lysis. In addition, there is some evidence for NK cell-mediated antiosteosarcoma activity in vivo. Post-operative osteomyelitis-associated inhibition of tumor growth was dependent on the activation of monocytes and NK cells in a murine osteosarcoma model [37]. In human osteosarcoma, treatment with interleukin (IL)-2 in a small cohort of patients resulted in NK cell activation, which was correlated with better clinical outcome [38]. Together, these studies suggest that exploitation of NK cell activity may be a suitable therapeutic tool in the adjuvant treatment of osteosarcoma. In the present study, we demonstrate that 


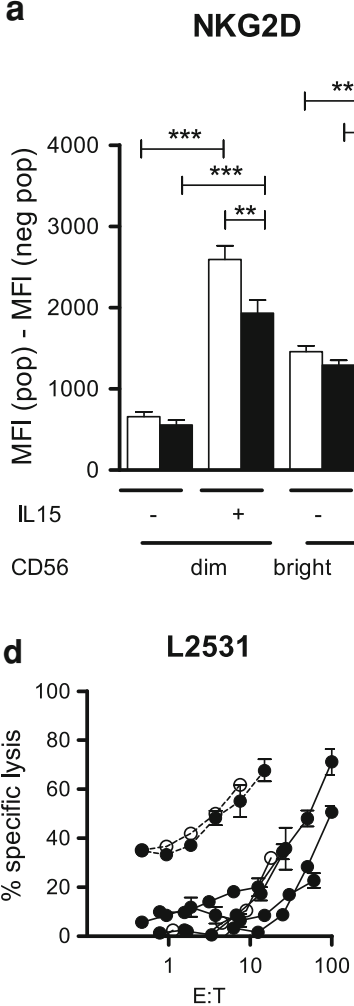

b

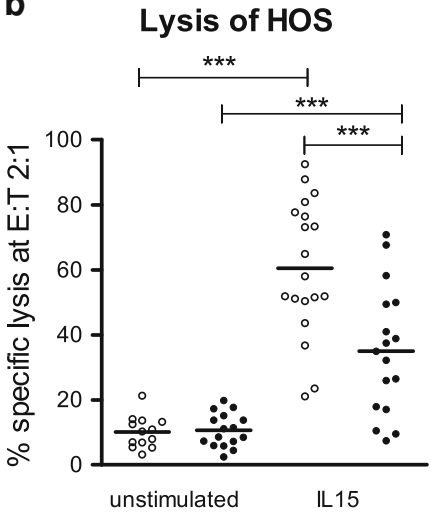

C NKG2D expression on IL-15 activated CD56dim NK cells

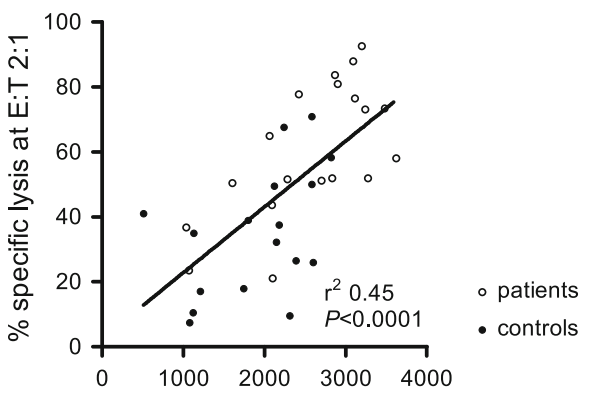

L2599

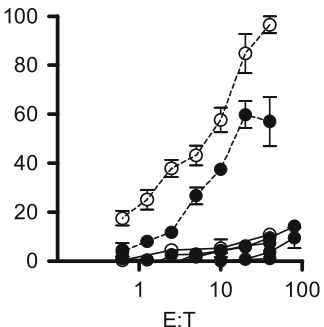

L2635

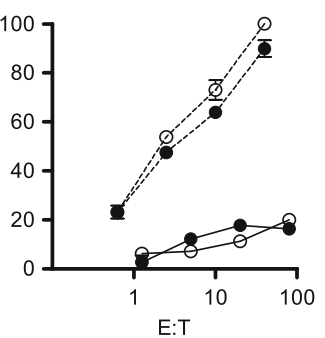

L2792

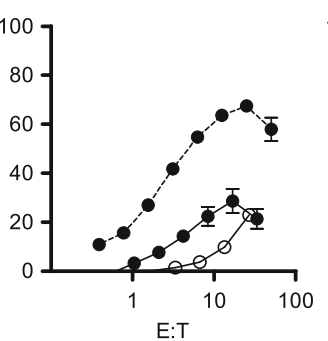

L2808

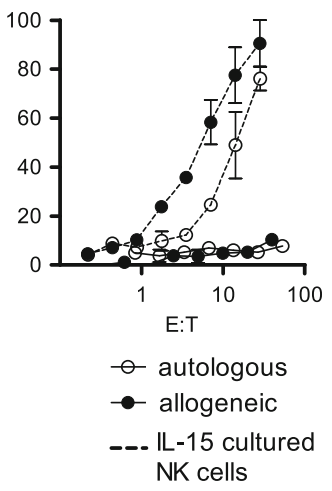

Fig. 5 a NKG2D level was similar in unstimulated NK cells of newly diagnosed osteosarcoma patients and healthy controls. Following culture for 3 days in IL15, there was a larger increase in the expression level of NKG2D in NK cells of patients. b Unstimulated PBMCs of 12 of 22 patients and 16 of 23 healthy controls and IL-15activated PBMCs of 19 of 22 patients and 17 of 23 controls were available for functional testing. NK cells of newly diagnosed osteosarcoma patients and of healthy controls lysed HOS at similar levels. Following IL-15 activation, NK cells of osteosarcoma patients showed a larger increase in cytotoxic activity than NK cells of healthy donors. c cytotoxicity of IL-15-activated NK cells correlated with level of NKG2D expression on the CD56dim subset (Pearson correlation coefficient). d primary osteosarcoma cell cultures were tested for sensitivity to lysis by autologous (open circle) and allogeneic (closed circle) NK cells. NK cells were unstimulated (solid lines) or 3 days IL-15 activated (dashed lines). Autologous IL15-activated NK cells were available for all patients except L2792. One-way analysis of variance (ANOVA) $P$-value $<0.0001$ for $a, b$, and c. Bonferroni's multiple comparison post-test; $P$-value $<0.05$ noted as $* ;<0.01$ as $* * ;<0.001$ as $* * *$ osteosarcoma cells are highly susceptible to NK cell-mediated cytolysis (Fig. 1). Osteosarcoma cells expressed activating NKG2D and DNAM-1 ligands in vivo as well as in vitro, and lysis was dependent on the interaction between these ligands on osteosarcoma cells and their receptors on NK cells (Figs. 2 and 3). Despite expression of the potentially inhibitory KIR ligand HLA class I by osteosarcoma cells, all cell lines and short-term cultures were highly sensitive to lysis by IL-15-activated NK cells (Table 1 and Figs. 1 and 5d). Together, these data suggest that the balance between expression of activating and inhibitory ligands in osteosarcoma is shifted toward activation.

To investigate whether NK cell-based immunotherapy is also feasible for patients with chemotherapy-resistant disease, we tested the susceptibility of in vitro selected chemotherapy-resistant osteosarcoma cells to NK cellmediated lysis. Methotrexate (MTX)-, doxorubicin (DX)-, or cisplatin (CDDP)-resistant variants of the cell lines SAOS-2 and U2-OS remained sensitive to lysis by IL-15activated NK cells (Fig. 4a). NK cells kill their targets by the release of perforin and granzyme containing granules and by the ligation of death receptors such as CD95 (Fas) [39, 40]. Expression of CD95 was lost in the CDDP- and DX-resistant SAOS-2 variants (Table 1 and Fig. 4), but dual blocking studies demonstrated only a minor role of Fas ligation in the lysis of osteosarcoma by cytokine-activated NK cells. Expression of Fas is frequently lost in osteosarcoma pulmonary metastases, but our data show that this will probably not hinder NK cell-based immunotherapeutic approaches [41-43]. 
Studies on the feasibility of immunotherapeutic strategies in bone tumors are often hampered by the technical difficulty to isolate viable fresh tumor cells for functional testing. To circumvent this problem, we used short-term cultured cells. Susceptibility to NK cell-mediated lysis was determined no later than at passage three. Four out of five cultures originated from patients with chemotherapyresistant disease (L2531, L2792, L2599, and L2808). Still, all were highly sensitive to lysis by cytokine-activated autologous and allogeneic NK cells (Fig. 5d). Importantly, our experiments on in vitro selected chemotherapy-resistant cells and on short-term cell cultures generated from patients with chemotherapy-resistant disease in vivo show that IL-15-activated NK cells are capable of lysis of osteosarcoma cells resistant to chemotherapeutic agents commonly used in high-grade osteosarcoma treatment.

In many tumor types, including Ewing sarcoma, host immune cells have decreased functionality when compared with healthy donor cells [13, 44, 45]. In these cases, using allogeneic immune cells instead of autologous cells is an attractive option to increase efficacy. However, it also increases the risk of serious complications such as graftversus-host-disease. Our data show that NK cells of osteosarcoma patients are as potent as NK cells of healthy controls in lysing osteosarcoma cells. Remarkably, upon activation with IL-15, patient-derived NK cells even showed a larger increase in the expression of NKG2D and granzymeB than healthy donor-derived NK cells, which correlated with an increased lysis of the osteosarcoma cell line HOS (Fig. 5a and Suppl. Fig. 2c). This, and the lysis of autologous tumor cells by ex vivo IL-15-activated NK cells, indicates that immunotherapeutic strategies employing activated autologous NK cells could be as successful as allogeneic NK cells in the treatment of osteosarcoma. In preclinical validation studies, we obtained evidence that IL15- and IL2-stimulated NK cells have similar cytolytic activity against various tumor cell lines [46].

In conclusion, chemotherapy-resistant and chemotherapy-sensitive osteosarcoma cells were lysed at high levels by NK cells, particularly when NK cells were cytokineactivated. Lysis of osteosarcoma cells was dependent on DNAM-1 and NKG2D, ligands of which were expressed by osteosarcoma cells both in vivo and in vitro. In contrast to what has been reported in patients with other tumor types, there was no intrinsic functional NK cell defect that could hamper antitumor activity. Our study shows a potential benefit of either activating NK cells in vivo by the administration of cytokines or adoptive transfer of ex vivo activated autologous or allogeneic NK cells in the treatment of high-grade osteosarcoma.

Acknowledgments This study is supported by a grant from the European Commission (EuroBoNeT, grant No 018814). EPB is funded by a grant from the Netherlands Organization for Health Research and Development (ZonMw grant 920-03-399). The authors wish to thank Monique van Ostaijen-ten Dam for help in the cytotoxicity assays, Maarten van Tol for fruitful discussions and provision of healthy donor PBMCs, Daniëlle de Jong for establishment and characterization of short-term tumor cell cultures, and Nicolette Leyerzapf, Judith Kroep, and Jakob Anninga for obtaining informed consent of osteosarcoma patients.

Open Access This article is distributed under the terms of the Creative Commons Attribution Noncommercial License which permits any noncommercial use, distribution, and reproduction in any medium, provided the original author(s) and source are credited.

\section{References}

1. Klein MJ, Parisien MV, Schneider-Stock R (2002) Osteogenic Tumours. In: Fletcher CDM, Unni KK, Mertens F (eds) World health classification of tumours. Pathology and genetics of tumours of soft tissue and bone. IARC Press, Lyon, pp 259-285

2. Bielack SS, Kempf-Bielack B, Delling G, Exner GU, Flege S, Helmke K, Kotz R, Salzer-Kuntschik M, Werner M, Winkelmann W, Zoubek A, Jurgens H, Winkler K (2002) Prognostic factors in high-grade osteosarcoma of the extremities or trunk: an analysis of 1,702 patients treated on neoadjuvant cooperative osteosarcoma study group protocols. J Clin Oncol 20:776-790

3. Buddingh EP, Anninga JK, Versteegh MI, Taminiau AH, Egeler RM, van Rijswijk CS, Hogendoorn PCW, Lankester AC, Gelderblom H (2010) Prognostic factors in pulmonary metastasized high-grade osteosarcoma. Pediatr Blood Cancer 54:216-221

4. Lewis IJ, Nooij MA, Whelan J, Sydes MR, Grimer R, Hogendoorn PCW, Memon MA, Weeden S, Uscinska BM, van Glabbeke M, Kirkpatrick A, Hauben EI, Craft AW, Taminiau AHM (2007) Improvement in histologic response but not survival in osteosarcoma patients treated with intensified chemotherapy: a randomized phase III trial of the European Osteosarcoma Intergroup. J Natl Cancer Inst 99:112-128

5. Marina N, Bielack S, Whelan J, Smeland S, Krailo M, Sydes MR, Butterfass-Bahloul T, Calaminus G, Bernstein M (2009) International collaboration is feasible in trials for rare conditions: the EURAMOS experience. Cancer Treat Res 152:339-353

6. Meyers PA, Schwartz CL, Krailo M, Kleinerman ES, Betcher D, Bernstein ML, Conrad E, Ferguson W, Gebhardt M, Goorin AM, Harris MB, Healey J, Huvos A, Link M, Montebello J, Nadel H, Nieder M, Sato J, Siegal G, Weiner M, Wells R, Wold L, Womer R, Grier H (2005) Osteosarcoma: a randomized, prospective trial of the addition of ifosfamide and/or muramyl tripeptide to cisplatin, doxorubicin, and high-dose methotrexate. J Clin Oncol 23:2004-2011

7. Meyers PA, Schwartz CL, Krailo MD, Healey JH, Bernstein ML, Betcher D, Ferguson WS, Gebhardt MC, Goorin AM, Harris M, Kleinerman E, Link MP, Nadel H, Nieder M, Siegal GP, Weiner MA, Wells RJ, Womer RB, Grier HE (2008) Osteosarcoma: the addition of muramyl tripeptide to chemotherapy improves overall survival-a report from the Children's Oncology Group. J Clin Oncol 26:633-638

8. Terme M, Ullrich E, Delahaye NF, Chaput N, Zitvogel L (2008) Natural killer cell-directed therapies: moving from unexpected results to successful strategies. Nat Immunol 9:486-494

9. Miller JS, Soignier Y, Panoskaltsis-Mortari A, McNearney SA, Yun GH, Fautsch SK, McKenna D, Le C, Defor TE, Burns LJ, Orchard PJ, Blazar BR, Wagner JE, Slungaard A, Weisdorf DJ, 
Okazaki IJ, McGlave PB (2005) Successful adoptive transfer and in vivo expansion of human haploidentical NK cells in patients with cancer. Blood 105:3051-3057

10. Ljunggren HG, Malmberg KJ (2007) Prospects for the use of NK cells in immunotherapy of human cancer. Nat Rev Immunol 7:329-339

11. Moretta A, Bottino C, Vitale M, Pende D, Cantoni C, Mingari MC, Biassoni R, Moretta L (2001) Activating receptors and coreceptors involved in human natural killer cell-mediated cytolysis. Annu Rev Immunol 19:197-223

12. Mistry AR, O'Callaghan CA (2007) Regulation of ligands for the activating receptor NKG2D. Immunology 121:439-447

13. Verhoeven DH, de Hooge AS, Mooiman EC, Santos SJ, ten Dam MM, Gelderblom H, Melief CJ, Hogendoorn PCW, Egeler RM, van Tol MJ, Schilham MW, Lankester AC (2008) NK cells recognize and lyse Ewing sarcoma cells through NKG2D and DNAM-1 receptor dependent pathways. Mol Immunol 45: 3917-3925

14. Lakshmikanth T, Burke S, Ali TH, Kimpfler S, Ursini F, Ruggeri L, Capanni M, Umansky V, Paschen A, Sucker A, Pende D, Groh V, Biassoni R, Hoglund P, Kato M, Shibuya K, Schadendorf D, Anichini A, Ferrone S, Velardi A, Karre K, Shibuya A, Carbone E, Colucci F (2009) NCRs and DNAM-1 mediate NK cell recognition and lysis of human and mouse melanoma cell lines in vitro and in vivo. J Clin Invest 119:1251-1263

15. Bottino C, Castriconi R, Pende D, Rivera P, Nanni $M$, Carnemolla B, Cantoni C, Grassi J, Marcenaro S, Reymond N, Vitale M, Moretta L, Lopez M, Moretta A (2003) Identification of PVR (CD155) and nectin-2 (CD112) as cell surface ligands for the human DNAM-1 (CD226) activating molecule. J Exp Med 198:557-567

16. El-Sherbiny YM, Meade JL, Holmes TD, McGonagle D, Mackie SL, Morgan AW, Cook G, Feyler S, Richards SJ, Davies FE, Morgan GJ, Cook GP (2007) The requirement for DNAM-1, NKG2D, and NKp46 in the natural killer cell-mediated killing of myeloma cells. Cancer Res 67:8444-8449

17. Karre K (2008) Natural killer cell recognition of missing self. Nat Immunol 9:477-480

18. Berghuis D, de Hooge ASK, Santos SJ, Horst D, Wertz EJ, van Eggermond MC, van den Elsen PJ, Taminiau AHM, Ottaviano L, Schaefer KL, Dirksen U, Hooijberg E, Mulder A, Melief CJM, Egeler RM, Schilham MW, Jordanova ES, Hogendoorn PCW, Lankester AC (2009) Reduced human leukocyte antigen expression in advanced-stage Ewing sarcoma: implications for immune recognition. J Pathol 218:222-231

19. Chang CC, Ferrone S (2007) Immune selective pressure and HLA class I antigen defects in malignant lesions. Cancer Immunol Immunother 56:227-236

20. Mohseny AB, Szuhai K, Romeo S, Buddingh EP, Briaire-de Bruijn I, de Jong D, van Pel M, Cleton-Jansen AM, Hogendoorn PCW (2009) Osteosarcoma originates from mesenchymal stem cells in consequence of aneuploidization and genomic loss of Cdkn2. J Pathol 219:294-305

21. Ottaviano L, Schaefer KL, Gajewski M, Huckenbeck W, Baldus S, Rogel U, Mackintosh C, de Alava E, Myklebost O, Kresse SH, Meza-Zepeda LA, Serra M, Cleton-Jansen AM, Hogendoorn PCW, Buerger H, Aigner T, Gabbert HE, Poremba C (2010) Molecular characterization of commonly used cell lines for bone tumor research: a trans-European EuroBoNet effort. Genes Chromosomes Cancer 49:40-51

22. Pasello M, Michelacci F, Scionti I, Hattinger CM, Zuntini M, Caccuri AM, Scotlandi K, Picci P, Serra M (2008) Overcoming glutathione S-transferase P1-related cisplatin resistance in osteosarcoma. Cancer Res 68:6661-6668

23. Serra M, Reverter-Branch MauriciD, Benini S, Shen JN, Chano T, Hattinger CM, Manara MC, Pasello M, Scotlandi K, Picci P
(2004) Analysis of dihydrofolate reductase and reduced folate carrier gene status in relation to methotrexate resistance in osteosarcoma cells. Ann Oncol 15:151-160

24. Serra M, Scotlandi K, Manara MC, Maurici D, Lollini PL, Degiovanni C, Toffoli G, Baldini N (1993) Establishment and characterization of multidrug-resistant human osteosarcoma celllines. Anticancer Res 13:323-329

25. Szuhai K, Ijszenga M, Tanke HJ, Rosenberg C, Hogendoorn PCW (2006) Molecular cytogenetic characterization of four previously established and two newly established Ewing sarcoma cell lines. Cancer Genet Cytogenet 166:173-179

26. Ruiter DJ, Ferrier CM, van Muijen GNP, Henzen-Logmans SC, Kennedy S, Kramer MD, Nielsen BS, Schmitt M (1998) Quality control of immunohistochemical evaluation of tumour-associated plasminogen activators and related components. Eur J Cancer 34:1334-1340

27. Cho D, Shook DR, Shimasaki N, Chang YH, Fujisaki H, Campana D (2010) Cytotoxicity of activated natural killer cells against pediatric solid tumors. Clin Cancer Res 16:3901-3909

28. Nakashima Y, Deie M, Yanada S, Sharman P, Ochi M (2005) Magnetically labeled human natural killer cells, accumulated in vitro by an external magnetic force, are effective against HOS osteosarcoma cells. Int J Oncol 27:965-971

29. Liebau C, Merk H, Schmidt S, Roesel C, Karreman C, Prisack JB, Bojar H, Baltzer AWA (2002) Interleukin-12 and interleukin-18 change ICAM-1 expression, and enhance natural killer cell mediated cytolysis of human osteosarcoma cells. Cytokines Cell Mol Ther 7:135-142

30. Honorati MC, Neri S, Cattini L, Facchini A (2003) IL-17 enhances the susceptibility of U-2OS osteosarcoma cells to NK cell lysis. Clin Exp Immunol 133:344-349

31. Kubista B, Trieb K, Blahovec H, Kotz R, Micksche M (2002) Hyperthermia increases the susceptibility of chondro- and osteosarcoma cells to natural killer cell-mediated lysis. Anticancer Res 22:789-792

32. Mariani E, Tarozzi A, Meneghetti A, Tadolini M, Facchini A (1996) Lytic activity of IL-2 and IL-12 stimulated NK cells against HOS osteosarcoma cell line. Boll Soc Ital Biol Sper 72:21-27

33. Mariani E, Tarozzi A, Meneghetti A, Cattini L, Facchini A (1997) Human osteosarcoma cell susceptibility to natural killer cell lysis depends on CD54 and increases after TNF alpha incubation. FEBS Lett 406:83-88

34. Mariani E, Tarozzi A, Meneghetti A, Cattini L, Facchini A (1998) TNF-alpha but not IL-1 and IL-6 modifies the susceptibility of human osteosarcoma cells to $\mathrm{NK}$ lysis. Int $\mathrm{J}$ Oncol 13:349-353

35. Mariani E, Meneghetti A, Tarozzi A, Cattini L, Facchini A (2000) Interleukin-12 induces efficient lysis of natural killersensitive and natural killer-resistant human osteosarcoma cells: The synergistic effect of interleukin-2. Scand J Immunol 51:618-625

36. Meneghetti A, Mariani E, Santi S, Riccio M, Cattini L, Paoletti S, Facchini A (1999) NK binding capacity and lytic activity depend on the expression of ICAM-1 on target bone tumours. Int J Oncol 15:909-914

37. Sottnik JL, U'ren LW, Thamm DH, Withrow SJ, Dow SW (2010) Chronic bacterial osteomyelitis suppression of tumor growth requires innate immune responses. Cancer Immunol Immunother 59:367-378

38. Luksch R, Perotti D, Cefalo G, Passerini CG, Massimino M, Spreafico F, Casanova M, Ferrari A, Terenziani M, Polastri D, Gambirasio F, Podda M, Bozzi F, Ravagnani F, Parmiani G, Bellani FF (2003) Immunomodulation in a treatment program including pre- and post-operative interleukin-2 and chemotherapy for childhood osteosarcoma. Tumori 89:263-268 
39. Chowdhury D, Lieberman J (2008) Death by a thousand cuts: granzyme pathways of programmed cell death. Annu Rev Immunol 26:389-420

40. Screpanti V, Wallin RPA, Ljunggren HG, Grandien A (2001) A central role for death receptor-mediated apoptosis in the rejection of tumors by NK cells. J Immunol 167:2068-2073

41. Gordon N, Koshkina NV, Jia SF, Khanna C, Mendoza A, Worth LL, Kleinerman ES (2007) Corruption of the Fas pathway delays the pulmonary clearance of murine osteosarcoma cells, enhances their metastatic potential, and reduces the effect of aerosol gemcitabine. Clin Cancer Res 13:4503-4510

42. Gordon N, Arndt CAS, Hawkins DS, Dohero DK, Inwards CY, Munsell MF, Stewart J, Koshkina NV, Kleinerman ES (2005) Fas expression in lung metastasis from osteosarcoma patients. J Pediatr Hematol Oncol 27:611-615

43. Koshkina NV, Khanna C, Mendoza A, Guan H, DeLauter L, Kleinerman ES (2007) Fas-negative osteosarcoma tumor cells are selected during metastasis to the lungs: the role of the fas pathway in the metastatic process of osteosarcoma. Mol Cancer Res 5:991-999
44. Konjevic G, Mirjacic MK, Vuletic A, Jovic V, Jurisic V, Babovic N, Spuzic I (2007) Low expression of CD161 and NKG2D activating NK receptor is associated with impaired NK cell cytotoxicity in metastatic melanoma patients. Clin Exp Metastasis $24: 1-11$

45. Garcia-Iglesias T, del Toro-Arreola A, barran-Somoza B, del Toro-Arreola S, Sanchez-Hernandez PE, Ramirez-Duenas MG, Balderas-Pena LM, Bravo-Cuellar A, Ortiz-Lazareno PC, neriNavarro A (2009) Low NKp30, NKp46 and NKG2D expression and reduced cytotoxic activity on NK cells in cervical cancer and precursor lesions. BMC Cancer 9:186

46. van Ostaijen-ten Dam M, Verhoeven D, Kraal K, Bongaerts R, van Bergen J, Ball LM, Lankester A, van Tol M, Zwaginga J (2010) Preclinical validation of an NK cell preparation: phenotype and function of NK cell products isolated via CliniMacs and subsequent ex vivo activation with IL-2 or IL-15. Bone Marrow Transplant 45:S302-S303 